\title{
The 3'-untranslated regions of c-mos and cyclin mRNAs stimulate translation by regulating cytoplasmic polyadenylation
}

\author{
Michael D. Sheets, ${ }^{1}$ Catherine A. Fox, ${ }^{1}$ Tim Hunt, ${ }^{2}$ George Vande Woude, ${ }^{3}$ and Marvin Wickens ${ }^{4}$ \\ Department of Biochemistry, College of Agricultural and Life Sciences University of Wisconsin, Madison, Wisconsin \\ 53706 USA
}

\begin{abstract}
Early in the development of many animals, before transcription begins, any change in the pattern of protein synthesis is attributable to a change in the translational activity or stability of an mRNA in the egg. As a result, translational control is critical for a variety of developmental decisions, including axis formation in Drosophila and sex determination in Caenorhabditis elegans. Previous work demonstrated that increases in poly(A) length can activate translation, whereas removal of poly(A) can prevent it. In this report we focus on the control of c-mos and cyclin A1, B1, and B2 mRNAs during meiotic maturation and after fertilization of frog eggs. We show that addition and removal of poly(A) from these mRNAs is extensively regulated: The time at which each mRNA receives or loses poly(A), as well as the number of adenosines it gains or loses, differ substantially. Signals in the $3^{\prime}$-untranslated region (UTR) of each mRNA are sufficient to reconstitute both the temporal and quantitative control of poly(A) addition: Chimeric mRNAs in which a luciferase-coding region is joined to the $3^{\prime}$ UTRs of cyclin $A 1$, cyclin B1, or c-mos mRNA, receive poly(A) of the same length and at the same time as do the endogenous mRNAs. Moreover, each 3' UTR also regulates translation of the chimeric mRNAs, determining when and how much translation of the luciferase reporter is stimulated during maturation. The magnitude of stimulation in luciferase activity varies from 5- to 100-fold, depending on the $3^{\prime}$ UTR. Translational stimulation by each 3' UTR requires poly(A) lengthening, as it is prevented by mutations that prevent that process. These results suggest that the 3' UTRs of cyclin and c-mos mRNAs control not only whether or not an mRNA is turned on during maturation, but when that activation occurs and to what extent. Translational control of c-mos mRNA, which may be achieved through regulation of poly(A) length, may be critical in the activation of maturation, and in the onset of cleavage divisions. Our findings, as well as those of others, suggest that even quite complex patterns of translational activation in the early embryo can be attained through the differential control of a common mechanism.
\end{abstract}

[Key Words: 3' UTR; poly(A); maternal mRNAs; translational control; cyclin; c-mos; oocyte maturation; development; Xenopus]

Received December 28, 1993; revised version accepted March 2, 1994.

In the earliest period of an animal's life, transcriptional control is irrelevant because the zygotic genome is inactive. Instead, any change in the pattern of protein synthesis during the earliest postfertilization period is attributable to regulation of mRNAs that were already present in the egg before fertilization-so-called maternal mRNAs. As a result, key decisions made during early development often rely on control of the translation, stability, or location of these mRNAs. For example, axis formation in Drosophila depends on proper localization

This paper is dedicated to Howard $M$. Temin.

Present addresses: ${ }^{1}$ Department of Molecular and Cellular Biology, University of California, Berkeley, California, ${ }^{2}$ Imperial Cancer Research Fund (ICRF), Clare Hall Laboratories, South Mimms, Potters Bar, Herts EN6 3LD, UK; ${ }^{3}$ Bionetics Research Inc., National Cancer Institute, Frederick, Maryland 21701 USA.

${ }^{4}$ Corresponding author. of bicoid and nanos mRNAs, and on the specific destruction of maternal hunchback mRNA (Driever and Nüsslein-Volhard 1988; Tautz and Pfeifle 1989).

Patterns of translational control in the early embryo are diverse. Maternal mRNAs that regulate key events in the embryo often are repressed during oogenesis and activated either during meiotic maturation or shortly after fertilization. glp-1 mRNA of Caenorhabditis elegans (Evans et al. 1994), and bicoid, nanos, and hunchback mRNAs of Drosophila (Driever and Nüsslein-Volhard 1988; Tautz and Pfeifle 1989) fall into this category. Other maternal mRNAs are activated earlier, before fertilization, or later, during early cleavages. Yet other maternal mRNAs are repressed. It is not yet known how many different biochemical mechanisms are responsible for this complex control.

The regulation of mRNAs encoding proteins involved 
in cell cycle regulation, such as cyclin, $\mathrm{p} 34^{\mathrm{cdc} 2}, \mathrm{CDK} 2$, and $\mathrm{CDC} 25$, provides a paradigm for the complexity of translational control during early development. Such mRNAs are present in the unfertilized eggs of many species, and contribute to the control of mitoses after fertilization. In frogs, the levels of cyclin A1, B1, and B2 mRNAs are constant throughout meiotic maturation and after fertilization, yet the levels of the corresponding proteins change dramatically (Kobayashi et al. 1991). Before meiotic maturation, translation of cyclin $\mathrm{B} 1$ and $\mathrm{B} 2$ mRNAs is more efficient than is that of cyclin Al mRNA, which essentially is off (Kobayashi et al. 1991). After maturation is initiated by adding progesterone, translation of all three mRNAs increases, although to different extents and at different times. For example, translation of cyclin B1 increases earlier during maturation than does that of cyclin Al. Although the precise functions of the cyclin A1, B1, and B2 proteins in early cell cycles are not yet fully understood, it is clear that their translation is vital. For example, translation of cyclin B maternal mRNA is required for proper embryonic cleavages after fertilization (Weeks et al. 1991).

In vertebrate oocytes and eggs, translation of c-mos mRNA is also critical in cell cycle control. Before fertilization, the ability of oocytes to advance from first to second meiosis requires translation of maternal c-mos mRNA (Sagata et al. 1988). Later, after fertilization, c-mos protein must be degraded for mitotic divisions to begin. Translational repression of maternal c-mos mRNA may also be important for this control, as injection of c-mos mRNA in excess can prevent the onset of cleavage divisions (Sagata et al. 1989).

Regulation of the length of poly(A) on specific maternal mRNAs appears to be a common means of translational activation in oocytes and early embryos. Cytoplasmic addition of poly(A) accompanies activation of many maternal mRNAs, whereas removal of poly(A) accompanies the inactivation of others (for review, see Jackson and Standart 1990; Bachvarova 1992; Wickens 19921. mRNAs that are critical in early development, such as fem-3 in C. elegans (Ahringer and Kimble 1991) and bicoid in Drosophila (Wharton and Struhl 1991), display this correlation. For some mRNAs, the mere increase in poly(A) length appears to be sufficient to cause the changes in translational activity, whereas in others it appears to be the act of adding the poly $(\mathrm{A})$, rather than final tail length that is critical (e.g., McGrew et al. 1989; Vassalli et al. 1989). Because mRNAs differ in when they gain or lose poly(A) (Dworkin et al. 1985; Paris et al. 1988; Paris and Philippe 1990), changes in poly(A) length could determine when a change in translational activity occurs. Similarly, differences in the length of poly $(\mathrm{A})$ added or removed might determine the magnitude of activation or repression, as translational stimulation appears to increase progressively with poly(A) length $(\mathrm{Mu}-$ nroe and Jacobson 1990; Gallie et al. 1991|. The involvement of poly $(\mathrm{A})$ length in translational control is complex, however, and may vary among mRNAs. For example, although a poly(A) tail stimulates translation of certain injected mRNAs dramatically, it has less effect on others (Galili et al. 1988). Moreover, in certain instances, poly(A) removal, not poly(A) addition, accompanies translational activation (e.g., Kleene 1989). Finally, repression of many maternal mRNAs may be achieved by mechanisms that do not involve poly(A) at all (e.g., Standart et al. 1990; Standart 1992).

The 3'-untranslated regions (3' UTRs) of specific maternal mRNAs have been implicated in a wide variety of processes, including translational control (McGrew et al. 1989; Vassalli et al. 1989; Standart et al. 1990; Wharton and Struhl 1991; Gavis and Lehmann 1992), mRNA degradation (Brown and Harland 1990), and intracellular localization of mRNAs (e.g., MacDonald and Struhl 1988; Gavis and Lehmann 1992; Mowry and Melton 1992). Sequences in the $3^{\prime}$ UTR also determine whether or not an mRNA receives poly(A) during frog oocyte maturation: mRNAs that contain a U-rich sequence (e.g., UUUUUAU) near AAUAAA acquire poly(A) (McGrew et al. 1989; Fox et al. 1989), whereas mRNAs that lack such a sequence lose their tails instead (Fox and Wickens 1990; Varnum and Wormington 1990). These U-rich sequences, sometimes called cytoplasmic polyadenylation elements (CPEs) (Paris and Richter 1990), can determine whether the translation of an mRNA will be activated during maturation (McGrew et al. 1989; Varnum and Wormington 1990; Huarte et al. 1992). Sequences near AAUAAA, perhaps including the CPE itself, may also determine whether an mRNA receives poly(A) after fertilization (Simon et al. 1992).

In this report we examine the regulation of translation and poly(A) length by the $3^{\prime}$ UTRs of cyclin and c-mos mRNAs. First, we examine the lengths of poly(A) present on each mRNA throughout maturation and after fertilization. Using this information as a starting point, we then examine how poly(A) length, and the time at which poly $(\mathrm{A})$ is added, are controlled. Our results suggest that the 3' UTRs of cyclin A1, B1, B2, and c-mos mRNAs may determine when and to what extent each mRNA is translated. In each case, translational stimulation requires poly $(\mathrm{A})$ addition. Thus, even complex patterns of translational activation in the early embryo may be achieved through the differential control of a common mechanism.

\section{Results}

\section{$\operatorname{Poly}(A)$ addition and removal are highly regulated}

To determine to what extent the length of poly $(\mathrm{A})$ on cyclin and c-mos maternal RNAs is controlled, we analyzed changes in poly $(\mathrm{A})$ length on these endogenous mRNAs during a single early period of development, encompassing oocyte maturation and first cleavage. To measure poly(A) lengths precisely, we used the following method (Mercer and Wake 1985; Brewer and Ross 1988). Oocytes were treated with progesterone to initiate oocyte maturation or were fertilized in vitro to initiate the first cleavage division. At various times afterward, total RNA was isolated and annealed to a DNA oligonucleotide complementary to a region 200 nucleotides 
from the poly(A) tail of the mRNA of interest. Half of each sample was also annealed to oligo(dT). Both samples were then treated with RNase $H$. The lengths of the $3^{\prime}$ UTR fragments were then determined by high-resolution Northern blotting, using a probe specific for the $3^{\prime}$ UTR. The length of poly(A) on a particular mRNA is the difference in length between RNAs treated with or without oligo(dT). The results obtained with five mRNAsc-mos, cyclin A1, cyclin B1, cyclin B2, and cytoskeletal actin-are presented in Figures 1 and 2 and are summarized in Figure 3.

The data demonstrate that the behavior of each mRNA is unique. c-mos and the three cyclin mRNAs all receive poly(A) during maturation but at different times and to different extents. Actin mRNA loses its tail. The differences among the mRNAs reveal that poly(A) addition and removal are regulated in at least five ways.

1. The time at which poly(A) is added is regulated. Whereas c-mos and cyclin B1 acquire poly(A) 2-4 hr after progesterone addition, cyclin $\mathrm{A} 1$ and $\mathrm{B} 2 \mathrm{mRNAs}$ undergo poly(A) lengthening later.

2. The length of poly(A) added is regulated. The poly(A) tail of cyclin B1 mRNA increases by 220 nucleotides (from 30 to 250 nucleotides), whereas the poly(A) tail of c-mos mRNA increases by only 70 nucleotides (from 50 to 120 nucleotides). Cyclin $\mathrm{A} 1$ and B2 mRNAs increase by 100 and 80 nucleotides, respectively.

3. The stability of the newly added poly $(\mathrm{A})$ is regulated. The poly(A) tails of cyclin mRNAs increase in length during maturation and are then stable. In contrast, extension of the tail of c-mos mRNA is transient: The 70 adenosines added to c-mos mRNA between 2 and $4 \mathrm{hr}$ after progesterone treatment are removed during the next $9 \mathrm{hr}$. As a result, the poly(A) tail of c-mos mRNA is the same average length before and after maturation.

4. Poly(A) removal after fertilization is regulated. After fertilization, although the poly(A) tail of c-mos mRNA is completely removed, the tails of cyclin $\mathrm{Al}$, $\mathrm{B} 1$, and $\mathrm{B} 2 \mathrm{mRNAs}$ persist.

5. The length of poly $(\mathrm{A})$ present before maturation begins is regulated. Before maturation, cyclin and c-mos mRNAs possess short poly(A) tails (Fig. 2). Furthermore, these short tails are of very discrete lengths $(40$ and 75 nucleotides on c-mos and 10, 40, and $60 \mathrm{nu}$ cleotides on cyclin B2) and persist throughout oogenesis (Fig. 2, stage 1 vs. stage 6).

From these results, we conclude that the lengths of poly(A) present on cyclin and c-mos mRNAs are highly regulated. In a single group of oocytes undergoing maturation, each mRNA gains or loses poly(A) at a characteristic time and to a characteristic extent. These results provide a precise description of the behavior of these endogenous mRNAs in vivo, and, therefore, serve as an unambiguous starting point at which to determine experimentally how regulation of poly(A) length is achieved and how it influences translational activity.
The 3' UTR determines the number of adenosines added both in vivo and in vitro

In vivo, cyclin B1 mRNA acquires approximately three times the number of adenosines as does c-mos mRNA ( $\sim 220$ vs. 70 nucleotides). To determine whether the sequences that control the number of adenosines added reside in the 3' UTR, we prepared labeled RNAs in vitro that contained the terminal 100 nucleotides of c-mos and cyclin B1 mRNAs and injected these into the cytoplasm of oocytes. Progesterone was added to initiate maturation. After maturation, RNA was extracted from the oocyte, and the length of poly(A) added to each RNA was determined by electrophoresis and autoradiography (Fig. 4A). The injected RNAs reproduce accurately the behavior of the endogenous mRNAs: c-mos RNA acquires poly(A) tails of 25-100 nucleotides, with an average length of 75 (Fig. 4A, lanes 4,5); in contrast, cyclin B1 RNA is extended by $40-300$ nucleotides, with an average of 200 (Fig. 4A, lanes 9,10). In the absence of progesterone, only a very short $(\sim 10$ nucleotide) oligo(A) tail is added to either RNA (Fig. 4A, lanes $2,3,7,8$ ), as reported previously using other RNAs (Fox et al. 1989).

Proper control of poly(A) length is preserved in vitro in a crude frog egg extract (Fig. 4B; Murray and Kirschner 1988; Paris and Richter 1990). The lengths of poly(A) added to cyclin B1 and c-mos RNAs in the egg extract were again determined by electrophoresis and compared directly to the length of poly(A) added to the same RNAs after injection. The lengths of poly $(\mathrm{A})$ added in vitro and in vivo are very similar (Fig. 4B). We conclude that the number of adenosines added to a given mRNA is determined by sequences in its $3^{\prime}$ UTR and that the transacting factors necessary for this control are present in the in vitro system.

\section{$\operatorname{Poly}(A)$ is sufficient to stimulate translation dramatically in vivo}

To test whether poly(A) itself is sufficient to stimulate translation throughout early development, as suggested by previous work (Drummond et al. 1985; Galili et al. 1988), we injected mRNAs prepared in vitro into frog oocytes and embryos. These mRNAs comprise the coding region of firefly luciferase, with or without a 50-nucleotide poly(A) tail (Fig. 5). They contain no 3' UTR.

The presence of the poly(A) tail stimulates accumulation of luciferase activity almost 200-fold in oocytes (Fig. $5)$. The stimulation by poly(A) is attributable to enhanced translation rather than enhanced mRNA stability, as mRNAs with and without a tail are equally stable after injection (see below). (We note, however, that the minority of mRNAs that actually associate with polysomes might be less stable without a tail.) Comparable enhancements of translation by $\operatorname{poly}(\mathrm{A})$ are observed when these mRNAs are injected into oocytes, cleaving 1-cell embryos and a single blastomere of a 16-cell embryo (Fig. 5). These results demonstrate that the presence of a poly(A) tail enhances translation throughout the early phases of frog development. Neither a $3^{\prime}$ UTR nor 


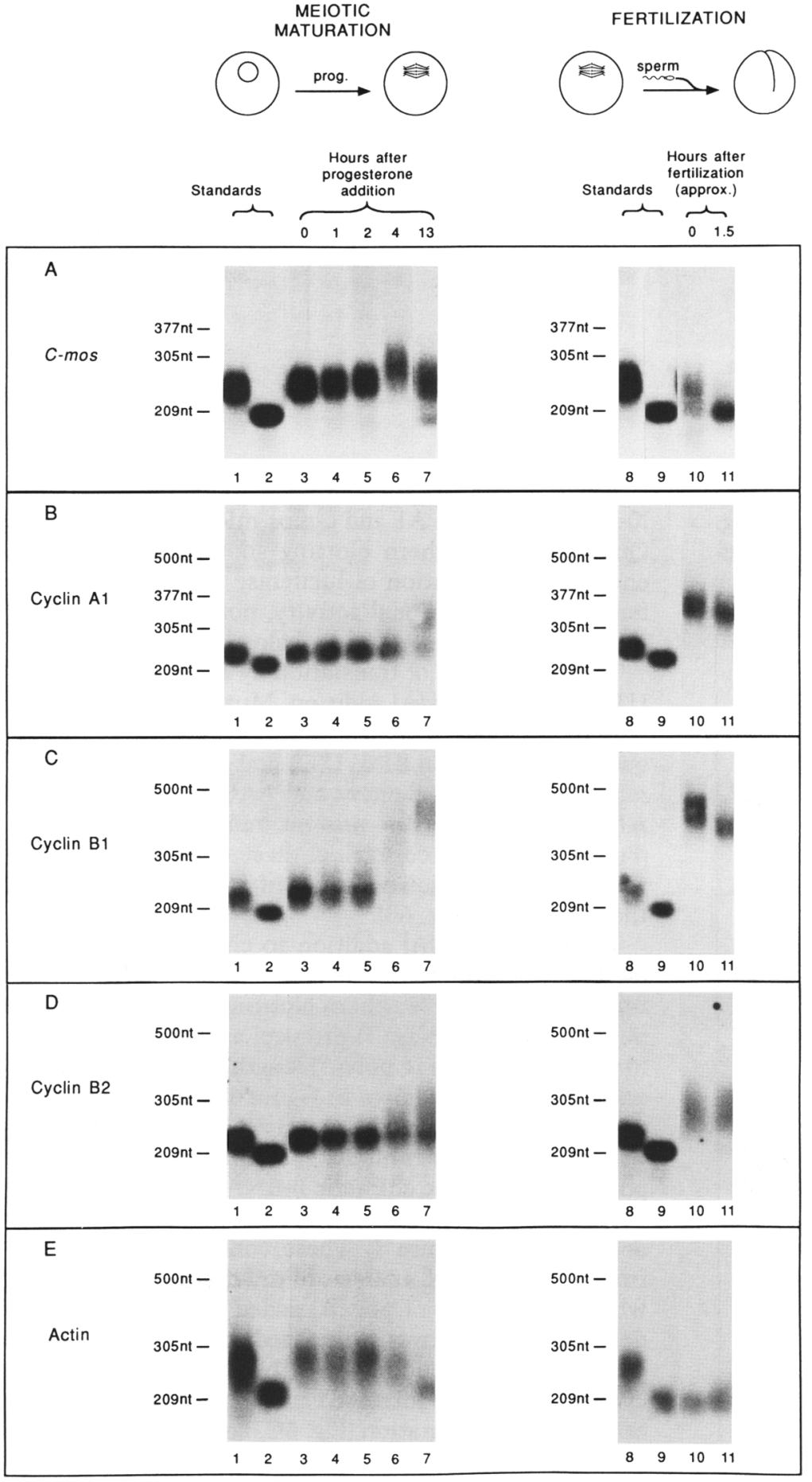

Figure 1. Poly(A) addition and removal are highly regulated. Determination of poly(A) tail lengths (see text). (A) c-mos mRNA; (B) cyclin Al mRNA; $(C)$ cyclin $\mathrm{B} 1$ mRNA; $(D)$ cyclin $\mathrm{B} 2$ mRNA; $(E)$ cytoskeletal actin mRNA. RNAs to be analyzed were obtained at different times after progesterone addition and after fertilization. (Lanes 1-7) Poly|A) changes during maturation. (Lanes 1,2) RNA standards. RNA from stage 6 oocytes was treated with complementary oligonucleotide alone and RNase $\mathrm{H}$ (lane 1), or with complementary oligonucleotide plus oligo $(\mathrm{dT})$ and RNase H (lane 2). (Lanes 3-7) RNA prepared at various times after progesterone addition, as indicated above each lane, was then treated with complementary oligonucleotide and RNase $\mathrm{H}$. In the experiment shown, $\mathrm{GVBD}_{50}$ (the time at which nuclear breakdown occurred in $50 \%$ of the oocytes) occurred at $4 \mathrm{hr}$. (Lanes 8-11) Poly(A) changes after fertilization. (Lanes 8,9) Same as lanes 1,2; (lane 10) RNA prepared from unfertilized eggs treated with complementary oligonucleotide and $\mathrm{RNase} \mathrm{H}_{\text {; }}$ (lane 11) RNA prepared from eggs $1.5 \mathrm{hr}$ after fertilization treated with complementary oligonucleotide and RNase $\mathrm{H}$. The oligonucleotides used for RNase $\mathrm{H}$ treatment were oligo $1(A)$, oligo $2(B)$, oligo $3(C)$, oligo $4(D)$, and oligo $5(E)$. See Materials and methods for their sequences and exact positions in the $3^{\prime}$ UTR. any other specific sequence in a maternal mRNA is required for the stimulation.

\section{3' UTRs of cyclin and $c$-mos mRNAs activate translation through polyadenylation but to different extents}

To elucidate the function of the $3^{\prime}$ UTRs of cyclin A1, $\mathrm{B} 1$, and c-mos mRNAs, we prepared chimeric mRNAs in which part of each $3^{\prime}$ UTR was joined to the luciferasecoding region (Fig. 6A). These chimeric mRNAs were injected into oocytes. Two hours later, progesterone was added to half of the oocytes to initiate maturation; the other half were incubated without progesterone. At the end of maturation, luciferase activity was determined. The ratio of luciferase activity present in the matured versus nonmatured oocytes was used to quantitate translational stimulation during maturation. 
Figure 2. Short discrete tails before maturation begins. Poly(A) tail lengths were measured using $30 \mu \mathrm{g}$ of total RNA from stage 6 oocytes and $1.5 \mu \mathrm{g}$ of stage $1-2$ oocytes (a $50: 50 \mathrm{mix}$ of stages 1 and 2 oocytes) as described in Materials and methods. $(A) \mathrm{c}$-mos mRNA; $(B)$ cyclin Al mRNA; $(C)$ cyclin B2 mRNA. $\mid+1$, lanes 2 and 4 in $A-C$ indicates samples to which oligo(dT) and RNase $\mathrm{H}$ were added to remove the poly(A) tail. The same oligonucleotides used in Fig. 1 for RNase $\mathrm{H}$ treatment were used here.

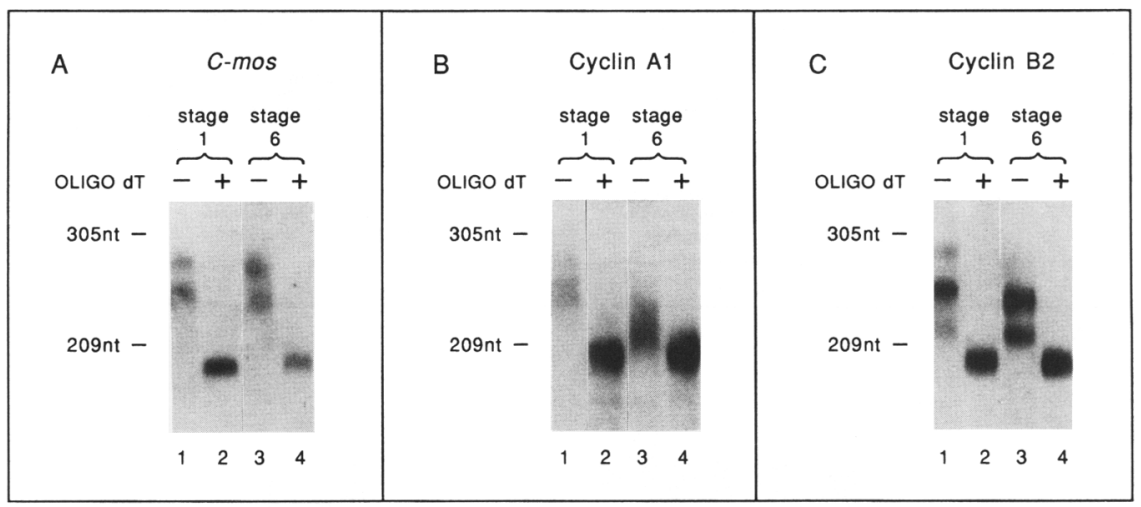

All three $3^{\prime}$ UTRs stimulate translation during maturation, as inferred by increases in luciferase activity (Fig. $6 \mathrm{~A})$. The magnitude of increase varies substantially be-

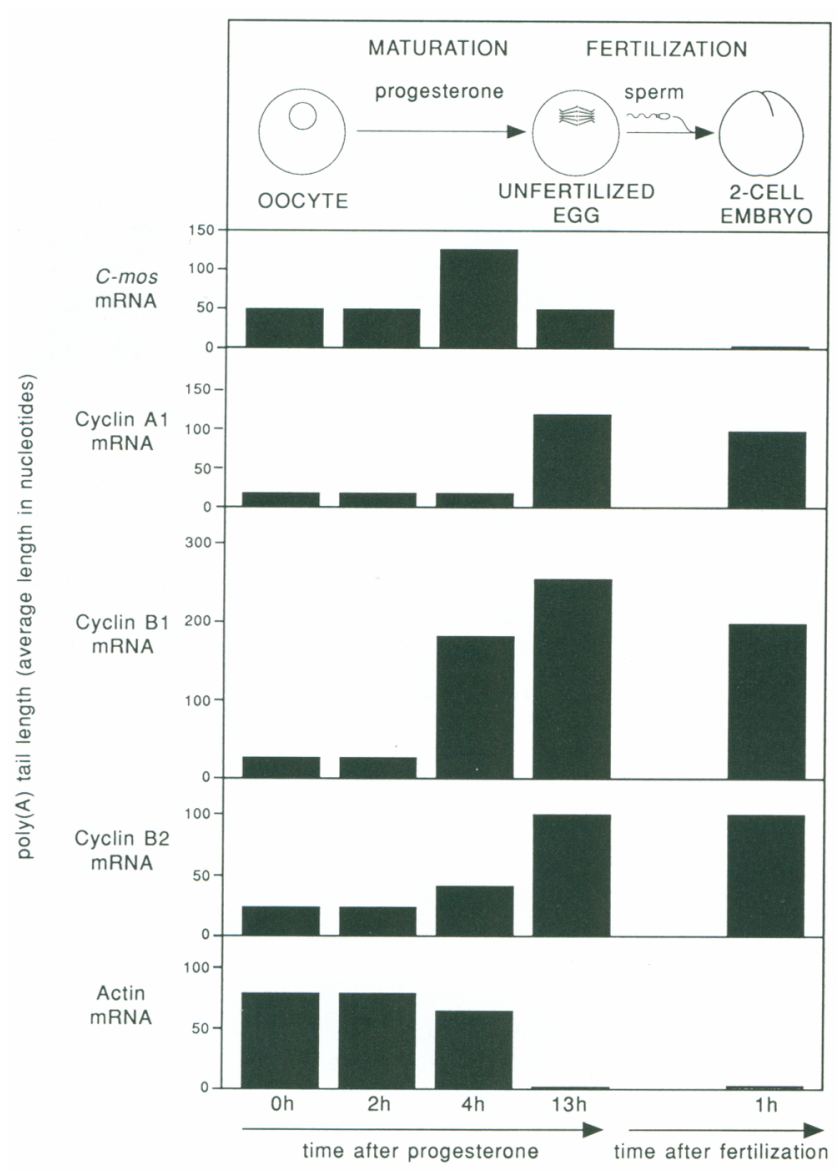

Figure 3. Summary of changes in Poly(A) lengths. Each panel represents data for a specific mRNA. The height of a horizontal bar indicates the average length of poly(A) present on a specific mRNA at a given time. Average lengths were calculated using an array detector (Beta Scope). Note that although tails are heterogeneous after maturation, they are, in some cases, discrete before maturation begins (see Fig. 2). Thus, c-mos tails are the same average length before and after maturation, but the two length distributions are very different. tween $3^{\prime}$ UTRs, from $\sim 75$-fold with cyclin B1 to 5- to 10-fold with cyclin A1 and c-mos mRNAs, respectively. Quantitative Northern blotting shows that the differences in accumulation of luciferase activity reflect differences in translational activity, not in the stability of the total injected mRNA (see below).

The stimulation of translation by each of the three 3 ' UTRs requires poly(A) addition. Mutations that prevent poly(A) addition-a point mutation in the AAUAAA sequence of the cyclin B1 3' UTR and short deletions that remove the U-rich element and AAUAAA of the cyclin $\mathrm{Al}$ and c-mos 3' UTRs-prevent translational activation (Fig. 6A). As expected, each of these mutations does prevent poly(A) addition without affecting the stability of the mRNA (see Fig. 6B).

To analyze poly(A) addition to chimeric mRNAs directly, we determined the length of poly(A) added to each injected mRNA by Northern blotting. We again used the oligonucleotide/RNase $\mathrm{H}$ protocol as in Figure 1; therefore, small changes in poly(A) length could be visualized and quantified. As shown in Figure 6B, each of the "wild type" 3' UTRs directed the synthesis of a poly(A) tail, whereas none of the mutant $3^{\prime}$ UTRs did. The lengths of poly (A) added to the chimeric mRNAs closely resembled the lengths added to their endogenous counterparts, as determined in Figure 1. These conclusions were confirmed by a detailed analysis of the cyclin B1 chimera in which the lengths of poly(A) added to injected and endogenous mRNAs were examined in the same group of oocytes (Fig. 6C). Luciferase mRNA carrying a wild-type cyclin B1 3' UTR increased in length by $\sim 300$ nucleotides during maturation (Fig. 6C, lanes 1,2). The length increase is attributable to poly (A) addition, as treatment of the RNA with oligo(dT) and RNase $H$ reduces the length back to that of the RNA incubated in oocytes without progesterone (Fig. 6C, cf. lane 3 with lane 1). A mutant mRNA in which AAUAAA had been changed to AAgAAA was stable during maturation, but failed to receive poly(A) (Fig. 6C, lanes 4,5). The length of poly(A) added to the wild-type mRNA is identical to the length of poly(A) added to real, endogenous cyclin Bl mRNA (Fig. 6C, lanes 6-8).

We conclude that each of the $3^{\prime}$ UTRs stimulates translation during maturation through a process that re- 


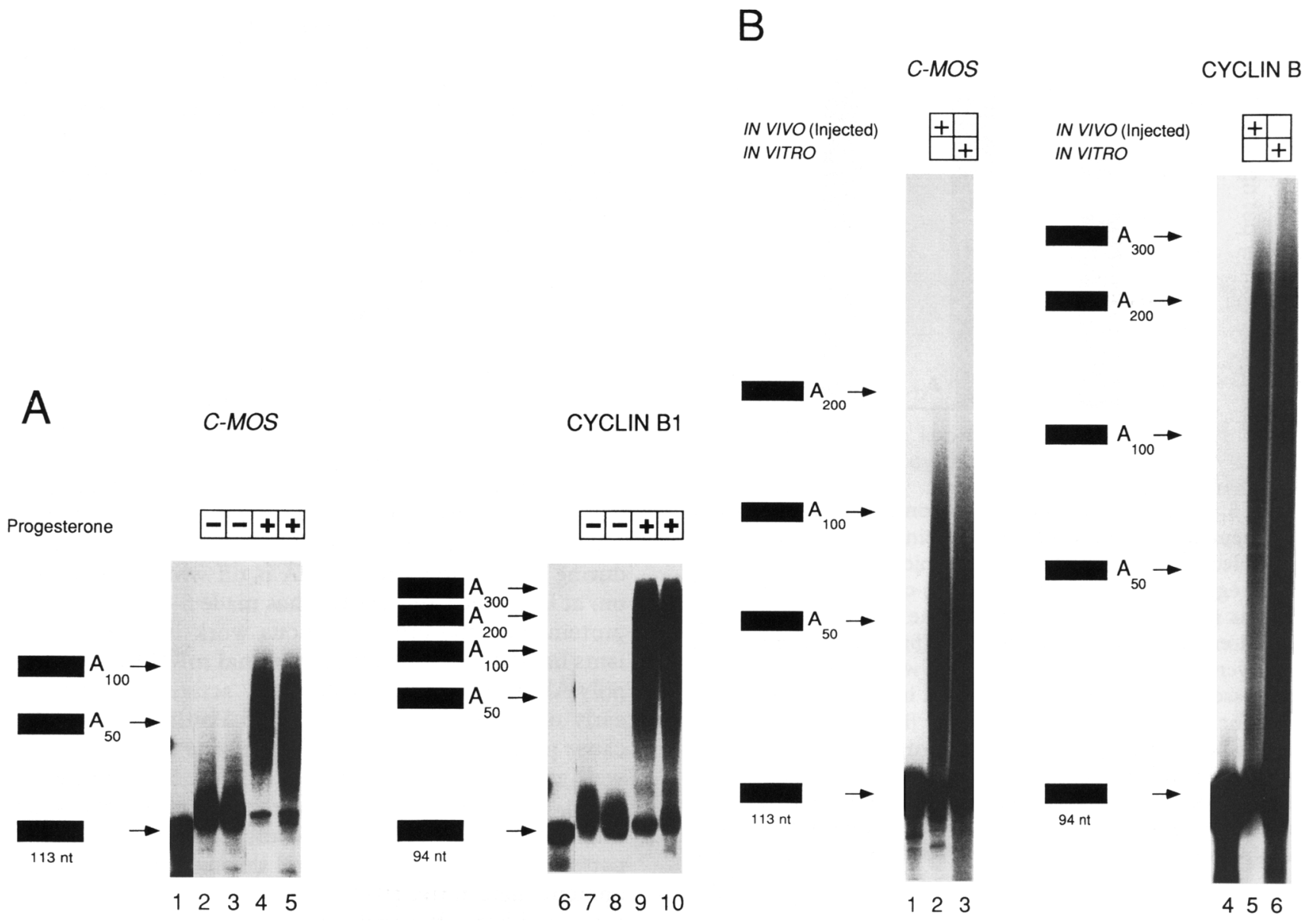

Figure 4. 3' UTRs determine the number of adenosines added. (A) Short segments of the $3^{\prime}$ UTRs of c-mos and cyclin B1 mRNAs determine the length of poly(A) added during maturation. Labeled c-mos $(-82 /+2)$ or cyclin B1 $(-82 /+2)$ RNAs were injected into the cytoplasms of frog oocytes. Oocytes were then incubated in the presence or the absence of progesterone, as indicated above each lane. RNA was extracted from separate, single oocytes and analyzed by gel electrophoresis. Each lane contains the RNA from an individual oocyte. (Lane 1) c-mos RNA, not injected into oocytes; (lanes 2,3) c-mos RNA, injected into oocytes, no progesterone; (lanes 4,5) c-mos RNA, injected into oocytes, progesterone added; (lane 6) cyclin B1 RNA, not injected into oocytes; (lanes 7,8) cyclin B1 RNA, injected into oocytes, no progesterone; (lanes 9,10) cyclin Bl RNA, injected into oocytes, progesterone added. $(B)$ Regulation of poly(A) length is preserved in vitro. Synthetic $-83 /+2 \mathrm{c}-$ mos (lanes $1-3)$ and $-83 /+2$ cyclin B1 (lanes $4-6)$ were injected into the cytoplasms of Xenopus oocytes, which were then exposed to progesterone (lanes 2,5), or were incubated in crude extracts prepared from unfertilized Xenopus eggs (lanes 3,6). RNAs were extracted and analyzed by denaturing gel electrophoresis. (Lane 1) c-mos RNA, not treated; (lane 2) c-mos RNA, injected into oocytes; (lane 3) c-mos RNA, incubated in vitro; (lane 4) cyclin B1 RNA, not treated; (lane 5) cyclin B1 RNA, injected into oocytes; (lane 6) cyclin B1 RNA, incubated in vitro.

quires poly(A) addition. The extent of translational stimulation observed with these three chimeras is correlated with the length of poly $(\mathrm{A})$ they receive.

\section{Temporal control of translation that requires $\operatorname{poly}(A)$ addition}

During maturation, translational stimulation of endogenous cyclin A1 mRNA occurs after stimulation of cyclin B1 (Kobayashi et al. 1991). Similarly, as shown in Figure 1 , poly $(\mathrm{A})$ is added to cyclin Al mRNA after cyclin B1 mRNA. These observations suggest that temporal control of polyadenylation may control the time at which translation is activated. To test this hypothesis, we injected chimeric mRNAs carrying either the cyclin Al or cyclin B1 3' UTR into oocytes and then assayed luciferase activity at various times after the addition of progesterone.

Translation of the cyclin B1 chimera is stimulated earlier than is that of the cyclin Al chimera (Fig. 7A). By 2.5 $\mathrm{hr}$ after the addition of progesterone, translation of the cyclin Bl chimera was already increased sixfold, whereas translation of the cyclin Al chimera was not detectably enhanced. Stimulation of cyclin A1 translation occurred only later, at approximately the time of nuclear breakdown during first meiosis (4.5 hr in Fig. 7A).

To determine when poly(A) was added to the chimeric mRNAs, the injected mRNAs were analyzed by Northern blotting after truncation by oligonucleotides and RNase $\mathrm{H}$. The cyclin B1 chimera received poly $(\mathrm{A})$ by the 


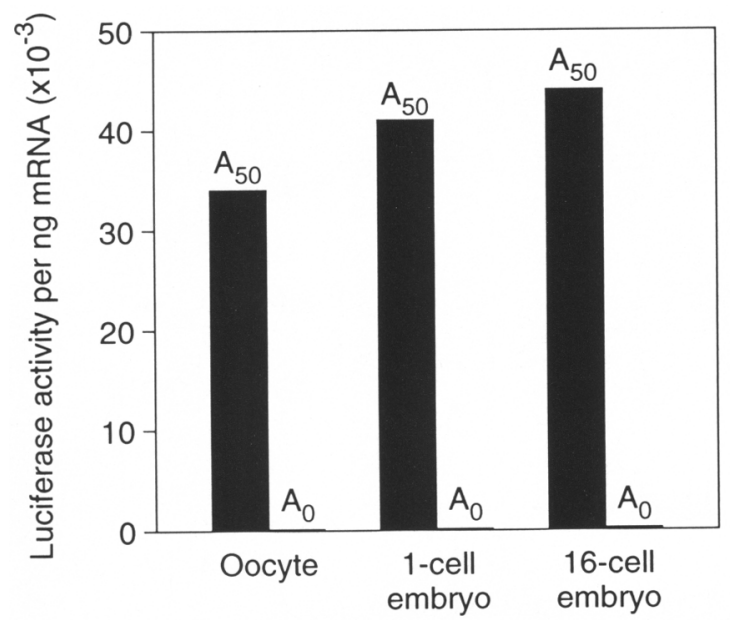

Figure 5. Poly(A) stimulates translation throughout early frog development. Luciferase mRNAs containing no poly $(\mathrm{A})\left[\mathrm{A}_{0}\right]$ or a 50 -nucleotide poly $(A)$ tail $\left[A_{50}\right]$ were injected into oocytes, fertilized eggs, or a single blastomere of 16-cell embryos. mRNA / I ng) was injected per cell except for the single blastomeres of 16-cell embryos, which received $125 \mathrm{pg}$. After injection, the cells were incubated for $2 \mathrm{hr}$. Extracts were then prepared and luciferase activity assayed as described in Materials and methods. The values of luciferase activity (in arbitrary units) per nanogram of mRNA injected are shown as vertical bars. Each value is the average of two experiments injecting each mRNA into 10 oocytes per experiment. All values except those obtained from 16-cell embryos were corrected for differences in mRNA stability using quantitative Northern blotting to determine the amount of $A_{0}$ and $A_{50}$ mRNAs remaining after injection (see Materials and methods). The differences in stability invariably were less than threefold.

earliest time point tested $(2.5 \mathrm{hr}$ after progesterone addition); in contrast, addition of poly(A) to the cyclin $\mathrm{Al}$ mRNA was not detectable until $1-2 \mathrm{hr}$ later (Fig. 7B). It is possible that the cyclin Al 3' UTR may have received a few adenosines by $2.5 \mathrm{hr}$ but may not readily be detectable in this assay. The lengths of poly $(\mathrm{A})$ added to the two chimeric mRNAs differ dramatically, again reflecting the behavior of the endogenous mRNAs.

The 3' UTRs of cyclin Al and B1 not only determine when translation is stimulated but how much. Once both mRNAs have been activated, they accumulate luciferase at very different rates (Fig. 7A). Because the halflife of luciferase protein in oocytes is $2-3 \mathrm{hr}$ (D. Daniel and $M$. Wickens, unpubl.), these observations strongly imply that the two mRNAs are translated at different rates.

We conclude that elements in the $3^{\prime}$ UTRs of cyclin $\mathrm{A} 1$ and $\mathrm{B} 1$ temporally control translational activation during maturation through a process requiring poly $|\mathrm{A}|$ addition. The same 3' UTRs also determine how efficiently an mRNA is translated once it has been activated.

\section{Discussion}

Our results lead to the following main conclusions. Addition and removal of poly(A) from c-mos, cyclin A1, B1, and B2 mRNAs are precisely controlled during oocyte maturation and after fertilization. Each mRNA receives or loses poly(A) at a characteristic time and to a characteristic extent. These properties are attributable to their 3' UTRs. Each 3' UTR stimulates translation during oocyte maturation, determining how much translation is stimulated and when during maturation that stimulation occurs. Translational stimulation invariably is correlated with, and dependent on, poly(A) addition. Therefore, we infer that translational stimulation of endogenous cyclin mRNAs (Kobayashi et al. 1991) is attributable, at least in part, to sequences in their $3^{\prime}$ UTRs through regulation of poly $(A)$ addition.

Our observations demonstrate that two 3' UTRs, both of which stimulate translation through polyadenylation, nonetheless can impose very different patterns of translational activity. The cyclin Al and Bl $3^{\prime}$ UTRs cause translation to turn on during maturation but at different times and at different rates. As a result, at early times during maturation, one mRNA is off while the other is on; at late times, one mRNA has made 5-10 times more protein than the other. Previous work in many organisms has demonstrated that maternal mRNAs change in poly(A) length and translational activity throughout early development (e.g., Paris and Phillippe 1990). Because poly(A) enhances translation after fertilization, as well as during oocyte maturation (Fig. 5; Simon et al. 1992), our results suggest that regulation of poly(A) addition mediated by $3^{\prime}$ UTRs could orchestrate complex patterns of translational control throughout early development, determining when different mRNAs are activated and how efficiently they are translated.

The presence or addition of a poly(A) tail does not dramatically affect the stability of the total mRNAs we have injected. For example, luciferase mRNAs are equally stable with and without a 50-nucleotide poly(A) tail (Fig. 5), and mutant luciferase/cyclin B1 mRNAs that do not receive poly(A) are no less stable than their wild-type counterparts, which are polyadenylated efficiently (Figs. 6 and 7). Nevertheless, if only a minority of the injected mRNAs are actively translated, it is possible that the stability of those few mRNAs that are translated is increased by their having a poly(A) tail. Polysome analysis will be required to determine whether this is the case. For the purposes of this discussion, we consider this hypothetical control of stability only upon association with polysomes to be a specific form of translational control.

The relationship between translational activity and poly(A) length may vary among mRNAs. For certain mRNAs, the magnitude of translational stimulation may simply increase with tail length, as appears to be true in vitro (Munroe and Jacobson 1990) and in electroporated cells (Gallie et al. 1991). For example, the cyclin B1 3' UTR causes a longer poly(A) tail to be added and stimulates translation to a much greater extent than does the cyclin A1 3' UTR. It is possible, however, that sequences in the $3^{\prime}$ UTR other than those that determine poly(A) length may modulate how efficiently these mRNAs are translated. Regardless, our results demonstrate that the 

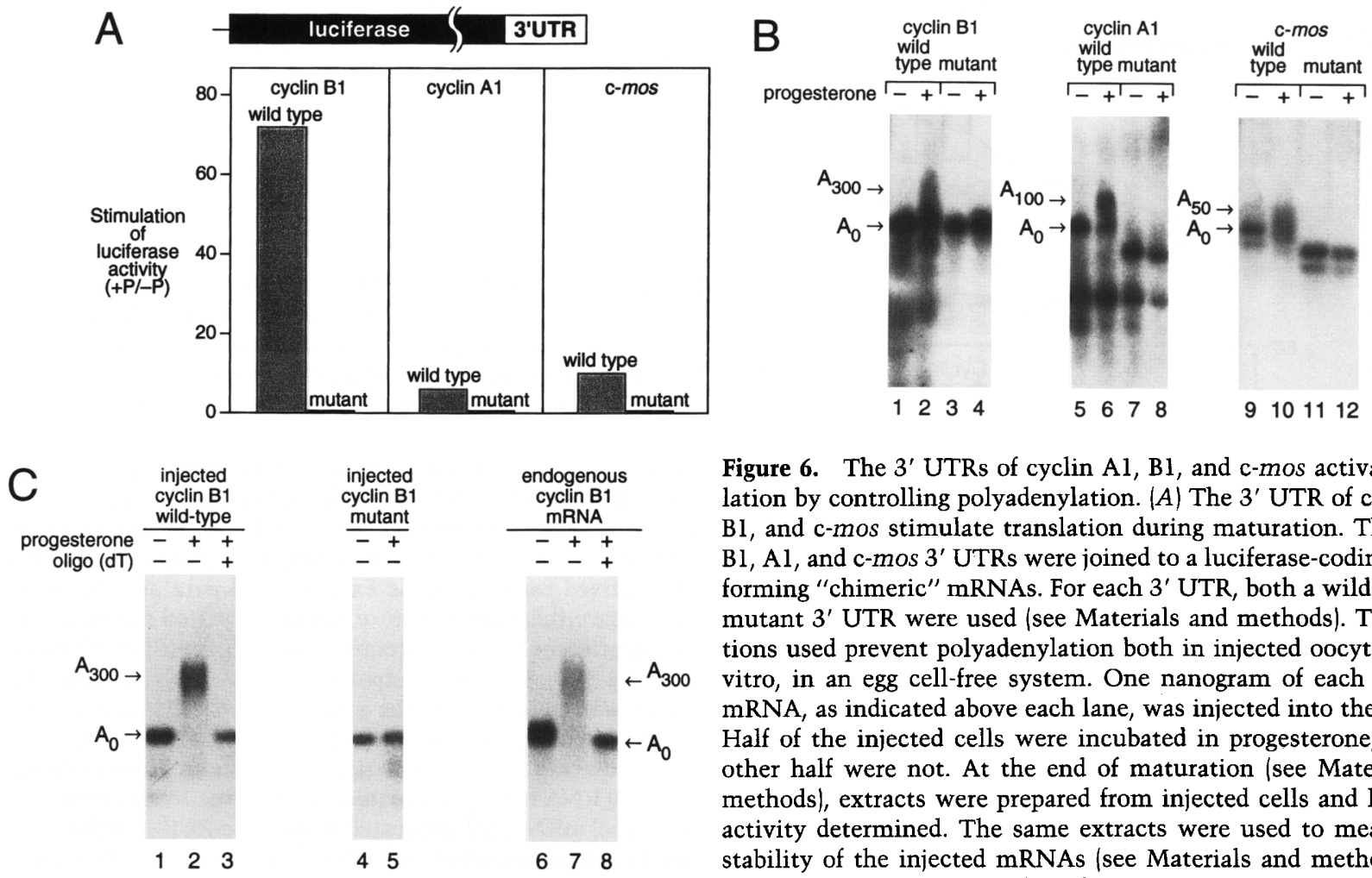

Figure 6. The $3^{\prime}$ UTRs of cyclin $\mathrm{Al}, \mathrm{B} 1$, and $\mathrm{c}-\mathrm{mos}$ activate translation by controlling polyadenylation. $(A)$ The $3^{\prime}$ UTR of cyclin Al, $\mathrm{Bl}$, and $\mathrm{c}-\mathrm{mos}$ stimulate translation during maturation. The cyclin $\mathrm{Bl}, \mathrm{Al}$, and c-mos 3' UTRs were joined to a luciferase-coding region, forming "chimeric" mRNAs. For each 3' UTR, both a wild-type and mutant 3' UTR were used (see Materials and methods). The mutations used prevent polyadenylation both in injected oocytes and in vitro, in an egg cell-free system. One nanogram of each chimeric mRNA, as indicated above each lane, was injected into the oocytes. Half of the injected cells were incubated in progesterone, and the other half were not. At the end of maturation (see Materials and methods), extracts were prepared from injected cells and luciferase activity determined. The same extracts were used to measure the stability of the injected mRNAs (see Materials and methods). The $y$-axis indicates the ratio of luciferase activity observed in matured vs. nonmatured oocytes $(+\mathbf{P} /-\mathbf{P})$. Each pair of bars represents wild-type (left $)$ and mutant (right) forms of a given $3^{\prime}$ UTR. The values obtained represent the average of 10 (the wild-type mRNAs) or 3 (the mutant mRNAs) experiments. In each experiment, oocytes from a different frog were used and each mRNA was injected into $20-30$ oocytes. (B) The $3^{\prime}$ UTR of cyclin Al, B1, and c-mos regulate poly(A) addition during oocyte maturation. RNA was isolated from oocytes injected with the indicated chimeric mRNAs. The data in $A$ and $B$ were obtained from the same injected oocytes. Poly(A) tail lengths were measured as described in Materials and methods. (Lanes 1,2) RNA from oocytes injected with luciferase/cyclin Bl (wild-type) mRNA and incubated in the absence (lane 1) or the presence (lane 2) of progesterone. RNAs were treated with a complementary oligonucleotide (oligo 8) and RNase H (lanes 1,2). (Lanes 3,4) RNA from oocytes injected with luciferase/cyclin B1 (mutant) mRNA and incubated in the absence (lane 3) or the presence (lane 4) of progesterone. RNAs were treated with a complementary oligonucleotide (oligo 8 ) and RNase $\mathrm{H}($ lanes 3,4 ). (Lanes 5,6$)$ RNA from oocytes injected with luciferasce/cyclin Al (wild-type) mRNA and incubated in the absence (lane 5) or the presence (lane 6) of progesterone. RNAs were treated with a complementary oligonucleotide (oligo 9) and RNase $\mathrm{H}($ lanes 5,6$)$. (Lanes 7,8) RNA from oocytes injected with luciferase/cyclin Al (mutant) mRNA and incubated in the absence (lane 7) or the presence (lane 8) of progesterone. RNAs were treated with a complementary oligonucleotide (oligo 9) and RNase $\mathrm{H}($ lanes 7,8). (Lanes 9,10) RNA from oocytes injected with luciferase/c-mos (wild type) mRNA an incubated in the absence (lane 9) or the presence (lane 10) of progesterone. RNAs were treated with a complementary oligonucleotide (oligo 7) and RNase H (lanes 9,10). (Lanes 11,12) RNA from oocytes injected with luciferase/ c-mos (mutant) mRNA and incubated in the absence (lane 11) or the presence (lane 12) of progesterone. RNAs were treated with a complementary oligonucleotide (oligo 7) and RNase $\mathrm{H}$ (lanes 7,8). Lengths of the poly(A) tails were measured by comparison with RNA markers of known size. $A_{0}, A_{100}$, and $A_{300}$ indicate the position to which the mRNAs would migrate if they carried poly(A) tails of 0 , 100 , or 300 nucleotides, as judged by comparison to molecular mass standards. $(C)$ The length of poly $(A)$ is added to the chimeric luciferase/cyclin B1 and endogenous cyclin Bl mRNAs is the same. RNA was isolated from the samples injected with luciferase/ cyclin B1 (wild-type) or luciferase/cyclin B1 (mutant) RNAs and from uninjected cells from the same female frog. Poly|A) tail lengths were measured as described in Materials and methods. (Lanes 1-3) RNA from oocytes injected with luciferase/cyclin B1 (wild-type) mRNA and incubated in the absence (lane 1) or the presence (lanes 2,3) of progesterone. RNAs were treated with a complementary oligonucleotide (oligo 6) and RNase $\mathrm{H}$ (lanes 1,2) or a complementary oligonucleotide plus oligo/dT) and RNase H (lane 3). (Lanes 4,5) RNA from oocytes injected with luciferase/cyclin Bl (mutant) mRNA incubated in the absence (lane 4) or presence (lane 5) of progesterone were treated with complementary oligonucleotides (oligo 6) and RNase $\mathrm{H}$. The complementary oligonucleotide used for the RNase H treatment of samples in lanes 1-5 hybridizes to the $3^{\prime}$ end of the luciferase gene (oligo 6) and the hybridization probe used for these lanes was complementary to the $3^{\prime}$ end of the luciferase gene (see Materials and methods). (Lanes 6-8) RNA from uninjected oocytes incubated in the absence (lane 6 ) or the presence (lanes 7,8 ) of progesterone were treated with a complementary oligonucleotide (oligo 3) and RNase $\mathrm{H}$ (lanes 6,7) or a complementary oligonucleotide plus oligo(dT) and RNase $\mathrm{H}$. The oligonucleotide used for the analysis in lanes $6-8$ is complementary to a region of the cyclin B1 mRNAs $3^{\prime}$ UTR (oligo 3). The hybridization probe used for detection in lanes 6-8 is complementary to the $3^{\prime}$ UTR of the cyclin Bl mRNA (see Materials and methods). Lengths of the poly(A) tails were measured by comparison with RNA markers of known size. $A_{300}$ indicates the position to which mRNAs with a poly(A) tail of 300 nucleotides would migrate, as judged by comparison to molecular mass standards. 
A
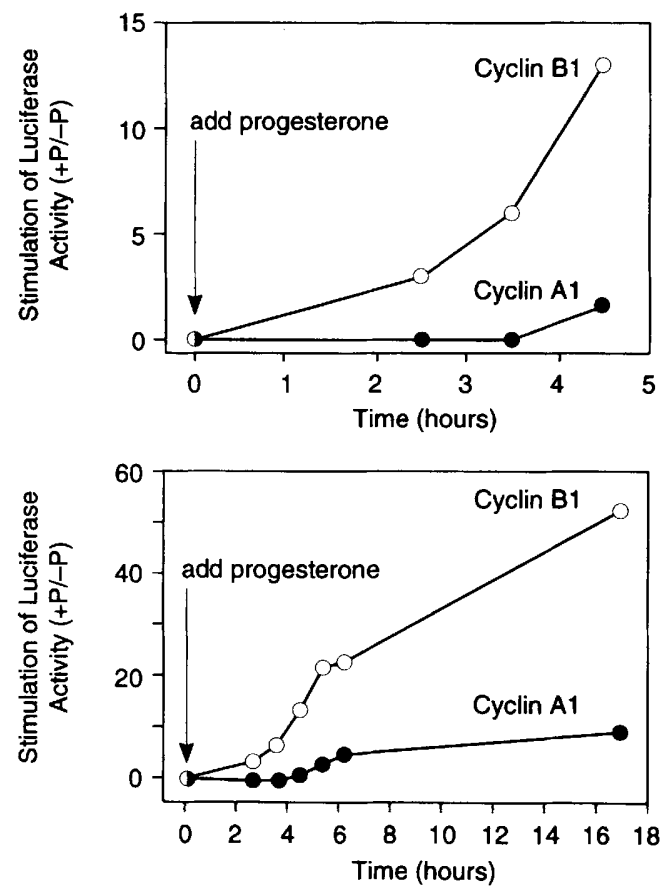

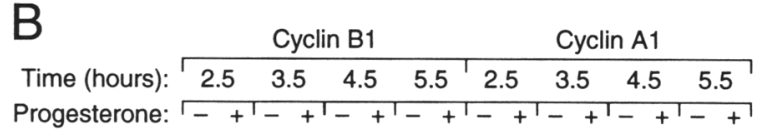

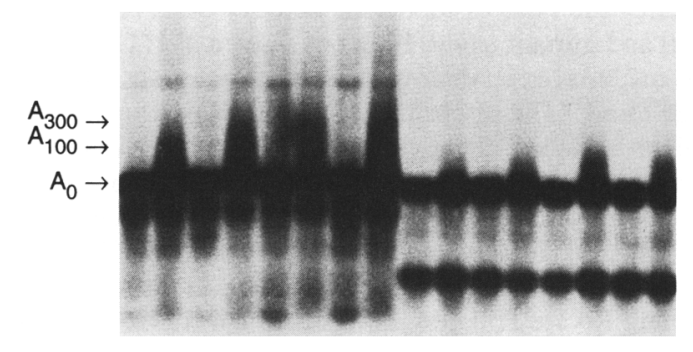

mere length of poly(A) present on an mRNA does not necessarily determine translational efficiency. In fully grown oocytes, the presence of a 50-nucleotide poly(A) tail is sufficient to stimulate translation of a luciferase reporter dramatically, yet cyclin Al mRNA, which has a tail of approximately that length, is effectively off (Kobayashi et al. 1991). Exogenous cyclin B1 and B2 mRNAs also carry short tails but are translated more efficiently than is cyclin Al (Kobayashi et al. 1991). In mouse oocytes, the shortening of the poly(A) tail of tPA mRNA is required for its repression before maturation (Huarte et al. 1992), yet other mRNAs with short tails are active.

Why should some mRNAs be stimulated by a short tail while others are not? One hypothesis is that different mRNAs vary in their dependence on poly $(A)$ length. Perhaps mRNAs that require poly(A) for translation might be intrinsically inefficient at initiation (e.g., because of sequences in their $5^{\prime}$ UTRs).

A second hypothesis proposes that certain mRNAs are repressed by a mechanism that has nothing to do with
Figure 7. Temporal control of translation and polyadenylation. (A) 3' UTRs of cyclin $\mathrm{Bl}$ and cyclin Al temporally regulate translation. One nanogram of luciferase/cyclin $\mathrm{Al}$ (wild type) or luciferase/cyclin B1 (wild type) RNA was injected into oocytes. Half of the injected cells were incubated in progesterone and the other half were not. At various times during maturation, extracts were prepared and luciferase activity was determined. The $y$-axis represents the ratio of luciferase activity observed in matured versus nonmatured oocytes $(+P /-P)$. The $x$-axis represents the time (in hr) after the addition of progesterone. Two plots derived from the same experimental data are shown to emphasize either early times, or the entire period examined. In this experiment $\mathrm{GVBD}_{50}$ occurred after $3.5 \mathrm{hr}$. (B) 3' UTRs of cyclin $\mathrm{Bl}$ and cyclin $\mathrm{Al}$ temporally regulate poly $(\mathrm{A})$ addition. mRNA was isolated from the same injected cells used for the activity measurements shown Fig. 6. Poly(A) tail lengths were measured as described in Materials and methods. (Lanes labeled Cyclin B) RNA from oocytes injected with luciferase/cyclin B1 (wild-type) mRNA and incubated in the absence (-) or the presence $(+)$ of progesterone. All RNAs were treated with a complementary oligonucleotide (oligo 8) and RNase $\mathrm{H}$. (Lanes labeled Cyclin A1) RNA from oocytes injected with luciferase/ cyclin Al (wild type) mRNA and incubated in the absence (-) or the presence $(+\mid$ of progesterone. All RNAs were treated with a complementary oligonucleotide (oligo 9). Lengths of the poly(A) tails were measured by comparison with RNA markers of known size: $A_{0}, A_{100}$, and $A_{300}$ indicate the positions to which the chimeric mRNAs would migrate if they had received 0,100 , or 300 nucleotides of poly(A), as judged by comparison with molecular mass standards.

having a short tail. "Unmasking" of maternal mRNAs can be achieved without a change in poly(A) length (Standart et al. 1990). Furthermore, activation of certain mRNAs appears to require the process of poly(A) addition, rather than the presence of a tail of a certain length (McGrew et al. 1989; Simon et al. 1992). Perhaps the repression or the "masking" of these mRNAs through their 3' UTRs is achieved by a mechanism that is independent of poly(A), involving, for example, locating the mRNA in a cytoplasmic microenvironment that is inefficient for translation, hiding the $5^{\prime}$ terminal cap structure, or causing the mRNA to form an inaccessible RNP structure. The Y-box proteins, non-sequence specific translational repressors, could play a role in this process (Tafuri and Wolffe, 1993). Addition of poly(A) might then derepress by altering these properties without there being any communication between the poly $(\mathrm{A})$ tail and the translation apparatus.

The cyclin Al 3' UTR receives poly $(\mathrm{A})$ and activates translation later than does the cyclin B1 3' UTR. Acti- 
vation of both mRNAs requires polyadenylation. Similarly, translation of maternal C12 mRNA in frogs is delayed until after fertilization by elements in its 3' UTR (Simon et al. 1992). One simple explanation of the temporal control of cyclin Al and B1 translation is that a negative element in the cyclin Al $3^{\prime}$ UTR delays its polyadenylation until late in maturation. An alternative hypothesis-that a cyclin Al-specific polyadenylation factor appears only late in maturation-has not been eliminated, however.

Negative translational control elements have now been identified genetically in several mRNAs. In flies, nanos can repress translation through an element located in the $3^{\prime}$ UTR of bicoid and hunchback mRNAs (Wharton and Struhl 1991; Gavis and Lehmann 1992). In worms, negative translational control elements have been identified in the $3^{\prime}$ UTRs of fem-3 (Ahringer and Kimble 1991), tra-2 (Goodwin et al. 1993), and glp-1 (Evans et al. 1994) mRNAs. In the few cases in which poly(A) length has been analyzed, mutations in these negative elements increase poly(A) length aberrantly. Clearly, for such mRNAs, the negative control elements could exert their effects on translation by repressing polyadenylation. In one simple model, the negative control elements could prevent the cytoplasmic polyadenylation machinery from gaining access to the mRNA in which they reside. Alternatively, negative control elements in 3' UTRs could repress translation by a mechanism that does not involve poly(A). In this hypothesis, polyadenylation might be a consequence, rather than a cause, of their activation. An increase in poly(A) length might sustain activation that was achieved by independent means. This may be the case with C12 mRNA which, upon injection into embryos, undergoes translational activation before a substantial tail has been added (Simon et al. 1992). A third hypothesis suggests that poly(A) addition and translational derepression are not causally connected at all but both are manifestations of a prior, upstream event.

Regulation of c-mos mRNA's poly(A) length may be critical both in the control of oocyte maturation and early mitotic cell cycles, as suggested previously (Fox et al. 1989; Wickens 1992). c-mos mRNA's translation is required for oocytes to advance through meiosis, presumably because c-mos protein is needed for an early step in maturation (Sagata et al. 1988, 1989). Our results show that during maturation, c-mos mRNA's poly(A) tail increases in length, and that the c-mos $3^{\prime}$ UTR stimulates translation of a luciferase reporter. These results suggest that addition of poly(A) to c-mos mRNA, by stimulating c-mos translation, may be a critical regulatory step in the induction of maturation by progesterone. After fertilization, c-mos mRNA loses its tail (Fig. 1), presumably inactivating its translation. Destruction of c-mos protein after fertilization is required to re-enter the cell cycle (Sagata et al. 1989). Whether inactivation of the mRNA is essential for the onset of mitosis is unknown; however, continued high levels of c-mos translation (generated by injecting high levels of c-mos mRNA) prevent the onset of cleavage, presumably by overwhelming the system that degrades the protein (Sagata et al. 1989).

Mechanisms of translational repression and activation in the early embryo are only beginning to be unravelled, and doubtless are diverse. Although our results suggest that mRNAs critical for cell cycle control may be regulated in part through the addition of poly(A), as are a number of other mRNAs, there is no compelling reason to believe that control of poly(A) length is the sole, or primary, mechanism of control in the early embryo. However, one principle to emerge from this and previous work appears to be very general: $3^{\prime}$ UTRs are critical during early development. Like promoters, the $3^{\prime}$ UTRs of maternal mRNAs appear to be mosaics of regulatory signals embedded in sequences that are unconstrained during evolution. Those signals can control when, where, and how much protein is produced from a mature, cytoplasmic mRNA, much as promoter elements do at the transcriptional level. Their importance in cytoplasmic control is unlikely to be peculiar to the egg and early embryo.

\section{Materials and methods}

\section{RNA isolation}

Xenopus laevis oocytes, eggs, and fertilized eggs were obtained as described (Newport and Kirschner 1982; Sagata et al. 1988; Fox et al. 1989). RNA was prepared as described previously (Fox et al. 1989). For the measurement of poly(A) tail length, total RNA was used.

\section{Measurement of $\operatorname{poly}(A)$ length}

Oligonucleotide/RNase $H$ treatment To measure the length of poly(A) on a specific endogenous mRNA, $30 \mu \mathrm{g}$ of total RNA was annealed to a specific DNA oligonucleotide and treated with RNase H (Mercer and Wake 1985; Brewer and Ross 1988). Each specific DNA oligonucleotide is complementary to a region 200 nucleotides (oligonucleotides 1-6) or 500 nucleotides (oligonucleotides 6-9) from the start of the poly(A) tail of the mRNA to be analyzed. Oligonucleotides used in RNase $\mathrm{H}$ treatment are given in Table 1. The positions of the sequences are given relative to either the nucleotide to which poly(A) is added, designated -1 (oligonucleotides 1-5), or to the first nucleotide of the termination codon (oligonucleotides 6-9).

High-resolution Northern blotting RNA samples were fractionated by length using two methods. In Figure 1, RNA samples were denatured with glyoxal and resolved on a $3 \%$ agarose gel (FMC, Nusieve 3:1 agarose) using $10 \mathrm{~mm}$ sodium phosphate (pH 7.0) as running buffer. The RNA was transferred to nylon membrane (Pall Biodyne A) by capillary action. In Figure 2, RNAs were separated on a denaturing polyacrylamide gel and transferred electrophoretically to charged membrane according to the manufacturers' directions (Zetaprobe, Bio-Rad). In all cases, RNA was fixed to the membrane by baking for $2 \mathrm{hr}$ at $80^{\circ} \mathrm{C}$ in a vacuum oven.

Filters were boiled for $3 \mathrm{~min}$ in $20 \mathrm{~mm}$ Tris- $\mathrm{HCl}(\mathrm{pH} 8.0)$, prehybridized, hybridized, washed, and exposed to X-ray film according to standard protocols (Maniatis et al. 1982; Schedl et al. 1984). Single-stranded DNA (ssDNA) (Wickens and Stephenson 1984) or RNA (Melton et al. 1984) probes used for hybridization were complementary to the last 200-300 nucleotides of 
Table 1. Oligonucleotides used in RNase $H$ treatment

\begin{tabular}{llll}
\hline Oligonucleotide & mRNA & Position & Sequence \\
\hline 1 & c-mos & -202 to -222 & GCAGCTGCTAAAGTCCATTC \\
2 & cyclin A1 & -205 to -225 & TTGTAGTAGTACATCCCAAC \\
3 & cyclin B1 & -193 to -214 & GCATACTTGTTCTTAACAGTC \\
4 & cyclin B2 & -203 to -223 & GAGGAGCCATAAGCTGAGGA \\
5 & cytoskeletal actin & -206 to -227 & CAGACCATTTTGAATGTTGGG \\
6 & luciferase & -140 to -161 & GGCGACGTAATCCACGATCTCT \\
7 & luciferase & -187 to -211 & CCAAAACAACAACGGCGGCGGGAAG \\
8 & luciferase & -461 to -485 & CATAGGTCCTCTGACACATAATTCG \\
9 & luciferase & -59 to -83 & TCGAGTTTTCCGGTAAGACCTTTCG \\
\hline
\end{tabular}

the mRNA, as follows: c-mos, ssDNA, last 181 nucleotides; cyclin $\mathrm{Al}$, ssDNA, last 326 nucleotides; cyclin $\mathrm{Bl}$, ssDNA, last 153 nucleotides; cyclin B2, ssDNA, last 181 nucleotides; cytoskeletal actin, RNA, last 260 nucleotides; luciferase, RNA last 60 nucleotides. The lengths of the RNA fragments were determined by comparison with standards of defined length using an array detector (BetaScope).

Plasmid construction, structure of RNA substrates, and nomenclature

All plasmids are named by the sequences that they contain: +1 designates the last nucleotide in the mRNA before the poly $(\mathrm{A})$ tail (i.e., the poly $(\mathrm{A})$ addition site).

$-83 /+2 c$-mos RNA A HindIII-EcoRI fragment containing the $3^{\prime}$ end of the c-mos cDNA was isolated from pXmos-8 ( $\mathrm{Sa}$ gata et al. 1988) and cloned into the HindIII-EcoRI sites of M13mp19 generating M13mp19 c-mos-1064/ + 17. An XbaI site was introduced into this plasmid at the poly(A) site using oligonucleotide-directed mutagenesis (Kunkel 1985). The DralEcoRI fragment from this construct containing the $3^{\prime}$ end of the c-mos CDNA was isolated and cloned into the EcoRI and the blunted BamHI site of pGEM3Z, creating pGEM $-83 /+2$ c-mos. This template was cleaved with $\mathrm{XbaI}$ and transcribed with SP6 RNA polymerase to yield a 113-nucleotide RNA. $-83 /+2 c-m o s$ RNA contains 29 nucleotides of vector sequence followed by 84 nucleotides of $c-m o s$ sequence.

$-83 /+2$ cyclin B1 RNA An insert containing the $3^{\prime}$ end of the cyclin $\mathrm{Bl}$ cDNA was created by annealing two single-stranded DNA oligonucleotides together. This insert was cloned into pGEM3Z cut with EcoRI and XbaI to create pGEM $-83 /+2$ cyclin Bl. The template was cut with $X b a I$ and transcribed with T7 RNA polymerase to yield a 94-nucleotide RNA. $-83 /+2$ cyclin B1 RNA contains 10 nucleotides of vector sequence followed by 84 nucleotides of cyclin $\mathrm{Bl}$ sequence.

Luciferase $A_{o}$ and luciferase $A_{50}$ mRNAs These RNAs were generated from pT7-Luc[BglII at stop codon] and pT7-Luc [minus $3^{\prime}$ UTR-A A $_{50}$ l plasmid templates kindly provided by D. Gallie (1991). To generate luciferase mRNA without a poly(A) tail, the pT7-Luc[BglII at stop codon] plasmid was cut with BglII. To generate luciferase mRNA with a 50-nucleotide poly(A) tail, the pT7-Luc [minus 3' UTR A 50 ] plasmid was cut with DraI. Both templates were transcribed using T7 RNA polymerase.

Luciferase/cyclin B1 mRNAs An insert containing the last 60 nucleotides of the cyclin Bl cDNA was generated by annealing two ssDNA oligonucleotides. This insert was then cloned into the BgIII and BamHI sites of pT7-Luc[BgIII at stop codon] generating $\mathrm{pLuc/cyclin} B \mathrm{~B}$. The oligonucleotides used to generate the insert contained equal amounts of $T$ and $G$ at the third position of the AATAAA sequence. This resulted in the production of two different plasmids: pLuc/cyclin Bl (wild type) contains the natural AATAAA sequence, whereas pLuc/cyclin Bl (mutant) contains the AAgAAA variant. This change in the AATAAA sequence prevents maturation-specific poly(A) addition (Fox et al. 1989). To generate luciferase/cyclin B1 mRNA, the pLuc/cyclin Bl plasmids were cleaved with BamHI and transcribed with T7 RNA polymerase. The luciferase/cyclin Bl mRNAs contain 1680 nucleotides of the luciferase gene followed by 60 nucleotides of the cyclin Bl 3' UTR.

Luciferase/c-mos mRNAs A HindIII-EcoRI fragment containing the $3^{\prime}$ end of the c-mos cDNA was isolated from pXmos-8 (Sagata et al. 1988) and cloned into the HindIII-EcoRI sites of pGEM $7 Z(\mathrm{f}+\mid$ generating pGEM $7 \mathrm{Z} / \mathrm{f}+\mid \mathrm{c}-\operatorname{mos}-1064 /+17$. An SpeI-XbaI fragment containing the $3^{\prime}$ end of the c-mos cDNA was isolated from this plasmid and blunt-ended with T4 DNA polymerase. This fragment was then cloned into the BglII (blunted with T4 DNA polymerase) and SmaI sites of pT7-Luc [BglII at stop codon] generating the plasmid pLuc/c-mos. To generate luciferase/c-mos mRNA, the pLuc/c-mos plasmid was cleaved with $X$ hol and transcribed with T7 RNA polymerase. Luciferase/c-mos mRNA contains 1680 nucleotides of the luciferase gene followed by the last 321 nucleotides of the c-mos 3' UTR. To generate the luciferase/c-mos mRNAs with a mutant c-mos 3' UTR, the pLuc/c-mos plasmid was cleaved with SspI and transcribed with T7 RNA polymerase. The SspI site is located 24 nucleotides $5^{\prime}$ of the AAUAAA sequence. The mutant luciferase/c-mos RNA contains 1680 nucleotides of the luciferase gene followed by 297 nucleotides of c-mos 3' UTR, lacking the AAUAAA and the U-rich sequences immediately upstream.

Luciferase/cyclin A1 RNAs A Sau3A fragment containing the $3^{\prime}$ UTR of the Xenopus cyclin Al cDNA was isolated and cloned into the BglII-BamHI sites of pT7-Luc [BglII at stop codon] generating $\mathrm{pLuc} / \mathrm{cyclin} \mathrm{Al}$. To generate luciferase/cyclin $\mathrm{Al}$ mRNA, the pLuc/cyclin Al plasmid was cleaved with SmaI and transcribed with T7 RNA polymerase. Luciferase/cyclin Al mRNA contains 1680 nucleotides of the luciferase gene followed by 445 nucleotides of the cyclin A1 3' UTR. To generate the luciferase/cyclin Al mRNAs with a mutant $3^{\prime}$ UTR, the $\mathrm{pLuc} / \mathrm{cyclin} \mathrm{Al}$ plasmid was cleaved with $\mathrm{XmnI}$ and transcribed with T7 RNA polymerase. The $X m n I$ site is located 42 nucleotides $5^{\prime}$ of the AAUAAA sequence. The mutant luciferase/ cyclin Al RNA contains 1680 nucleotides of the luciferase gene followed by 380 nucleotides of the cyclin Al 3' UTR, lacking 
the AAUAAA sequence and the U-rich sequences immediately upstream.

Preparation of RNA substrates and oocyte injections

RNA substrates were prepared and injected into oocytes as described (Fox et al. 1989). For the experiments in Figure 5, 2 fmoles of RNA were injected into each cell. For the experiments in Figures 6 and 7, 1-10 ng of mRNA was injected into each cell. Our results are independent of the amount of RNA injected, as we used the ratio of luciferase activity in matured versus nonmatured oocytes to measure translational stimulation in response to progesterone, rather than absolute values of luciferase activity.

\section{Maturation of oocytes}

Oocytes were matured by incubating in $10 \mu \mathrm{g} / \mathrm{ml}$ of progesterone. In experiments in which samples were taken at the "end of maturation", this was three to four times $\mathrm{GVBD}_{50}$ (the time after progesterone addition when half of the oocytes display a white spot).

\section{Measuring luciferase activity}

Protocols and reagents for cell homogenization and initiating luminescence were obtained from Promega (Madison, WI). Luminescence was measured using a liquid scintillation counter with the coincidence counter turned off. For each experiment several cells were injected with RNA and the cells pooled before homogenization.

To ensure that our measurements of luciferase activity reflect true differences in mRNA translation and not differences in mRNA stability, we determined the amount of RNA remaining after injection using quantitative Northern blotting and analysis with either a BetaScope array detector (Betagen) or a PhosphorImaging device (Molecular Dynamics). The adjusted luciferase activity, used in all of the figures, was derived by dividing the absolute values for luciferase activity per cell by the amount of luciferase activity in each cell.

\section{Preparation of Xenopus egg extracts and in vitro poly $(A)$ addition assays}

Cytostatic factor-arrested extracts of Xenopus eggs were prepared according to the method of Murray and Kirschner (1989). The crude extract was exchanged into a buffer containing 50 $\mathrm{mm}$ Tris- $\mathrm{HCl}\left(\mathrm{pH} 7.9\right.$ at $\left.25^{\circ} \mathrm{C}\right), 1 \mathrm{mM}$ DTT, $10 \mathrm{~mm} \mathrm{KCl}, 150 \mu \mathrm{M}$ EDTA, and $15 \%$ (vol/vol) glycerol. Polyadenylation reactions contained 2 fmoles of RNA substrate, $6 \mu$ l of extract $\{\sim 180 \mu \mathrm{g}$ protein), $7.5 \mathrm{~mm}$ creatine phosphate, $1 \mathrm{mM}$ ATP, $100 \mu \mathrm{M}$ EDTA, $1 \mathrm{mM} \mathrm{MgCl}, 20$ units RNAsin, and $6.5 \mu \mathrm{g}$ of yeast RNA. The total reaction volume was $10 \mu l$. Reactions were incubated at $25^{\circ} \mathrm{C}$ for $20 \mathrm{~min}$.

\section{Extraction and analysis of RNA}

Each oocyte or in vitro reaction mixture was homogenized in $200 \mu \mathrm{l}$ of $50 \mathrm{~mm}$ Tris- $\mathrm{HCl}$ (pH 7.9), $5 \mathrm{~mm}$ EDTA, 2\% SDS, 300 $\mathrm{mM} \mathrm{NaCl}$, and $250 \mathrm{mg} / \mathrm{ml}$ of proteinase $\mathrm{K}$. The homogenate was extracted with phenol/chloroform and the aqueous phase was precipitated with ethanol. Each RNA pellet was resuspended in $10 \mu \mathrm{l}$ of water and analyzed by electrophoresis through $6 \%$ polyacrylamide gels containing $7 \mathrm{M}$ urea (Sanger and Coulson 1978). Autoradiographic exposures of the dried gels were generally for 6-24 hr with an intensifying screen.

\section{Acknowledgments}

M.S. and M.W. are especially grateful to John Gerhart, not only for his understanding and enthusiastic support of this work, but also for his inspirational performance as a mentor to undergraduates. We are also grateful to an anonymous reviewer who help us clarify certain ambiguities and so improved the text. Judith Kimble's comments on the manuscript were invaluable, as were the critical discussions and comments from the Wickens laboratory and RiboGroup. We appreciate Mike Wu's assistance in providing copious quantities of defolliculated oocytes. Dr. Daniel Gallie generously provided plasmids containing various versions of the luciferase gene. Laura VanderPloeg and Adam Steinberg did an excellent job of preparing figures quickly, accurately, and repeatedly. We gratefully acknowledge that this work was supported by a National Institutes of Health (NIH) research grant (GM31892) and a Research Career Development Award (GM00521) to M.W., an NIH post-doctoral fellowship (GM15203-02) to M.S., and an NIH research grant (GM19363) to John Gerhart.

The publication costs of this article were defrayed in part by payment of page charges. This article must therefore be hereby marked "advertisement" in accordance with 18 USC section 1734 solely to indicate this fact.

\section{References}

Ahringer, J. and J. Kimble. 1991. Control of the sperm-oocyte switch in Caenorhabditis elegans hermaphrodites by the fem-3 3' untranslated region. Nature 349: 346-348.

Brewer, G. and J. Ross. 1988. Poly(A) shortening and degradation of the A+U-rich sequences of human c-myc mRNA in a cell free system. Mol. Cell. Biol. 8: 1697-1708.

Brown, B.D. and R.M. Harland. 1990. Endonucleolytic cleavage of a maternal homeo box mRNA in Xenopus oocytes. Genes \& Dev. 4: 1925-1935.

Driever, W. and C. Nüsslein-Volhard. 1988. A gradient of bicoid protein in Drosophila embryos. Cell 54: 83-93.

Drummond, D.R., J. Armstrong, and A. Coleman. 1985. The effect of capping and polyadenylation on the stability, movement and translation of synthetic messenger RNAs in Xenopus oocytes. Nucleic Acids Res. 13: 7375-7392.

Dworkin, M.B., A. Shrutkowski, and R.E. Dworkin. 1985. Mobilization of specific maternal RNA species into polysomes after fertilization in Xenopus laevis. Proc. Natl. Acad. Sci. 82: 7636-7640.

Evans, T.C., S.L. Crittenden, V. Kodoyianni, and J. Kimble. 1994. Translational control of maternal glp-1 mRNA establishes an asymetry in the C. elegans embyro. Cell 77: 1-20.

Fox, C.A. and M. Wickens. 1990. Poly(A) removal during oocyte maturation: A default reaction selectively prevented by specific sequences in the $3^{\prime}$ UTR of certain maternal mRNAs. Genes \& Dev. 4: 2287-2298.

Fox, C.A., M.D. Sheets, and M.P. Wickens. 1989. Poly(A) addition during maturation of frog oocytes: Distinct nuclear and cytoplasmic activities and regulation by the sequence UUUUUAU. Genes \& Dev. 3: 2151-2162.

Galili, G., E. Kawata, L.D. Smith, and B.A. Larkins. 1988. Role of the $3^{\prime}$-poly(A) sequence in translational regulation of $\mathrm{mR}$ NAs in Xenopus laevis oocytes. J. Biol. Chem. 263: 5764 5770.

Gallie, D.R. 1991. The cap and poly(A) tail function synergistically to regulate mRNA translational efficiency. Genes \& Dev. 5: 2108-2116.

Gallie, D.R., J.N. Feder, R.T. Schimke, and V. Walbot. 1991. Post-transcriptional regulation in higher eukaryotes: The 
role of the reporter gene in controlling expression. Mol. \& Gen. Genet. 228: 258-264.

Gavis, E.R. and R. Lehmann. 1992. Localization of nanos RNA controls embryonic polarity. Cell 71: 301-313.

Goodwin, E.B., P.G. Okkema, T.C. Evans, and J. Kimble. 1993. Translational regulation of tra-2 by its 3 ' untranslated region controls sexual identity in C. elegans. Cell 75: 329-339.

Huarte, J., A. Stutz, M.L. O'Connell, P. Gubler, D. Belin, A.L. Darrow, S. Strickland, and J.D. Vassalli. 1992. Transient translational silencing by reversible mRNA deadenylation. Cell 69: 1021-1030.

Kleene, K.C. 1989. Poly(A) shortening accompanies the activation of translation of five mRNAs during spermiogenesis in the mouse. Development 106: 367-373.

Kobayashi, H., J. Minshull, C. Ford, R. Golsteyn, R. Poon, and T.J. Hunt. 1991. On the synthesis and destruction of A- and B-type cyclins during oogenesis and meiotic maturation in Xenopus laevis. J. Cell Biol. 114: 755-765.

Kunkel, T.A. 1985. Rapid and efficient site-specific mutagenesis without phenotype selection. Proc. Natl. Acad. Sci. 82: 488492.

MacDonald, P.M. and G. Struhl. 1988. cis-acting sequences responsible for anterior localization of bicoid mRNA in Drosophila embryos. Nature 336: 595-598.

Maniatis, T., E.F. Fritsch, and J. Sambrook. 1982. Molecular cloning: A laboratory manual. Cold Spring Harbor Laboratory, Cold Spring Harbor, New York.

McGrew, L.L., E. Dworkin-Rastl, M.B. Dworkin, and J.D. Richter. 1989. Poly|A/ elongation during Xenopus oocyte maturation is required for translational recruitment and is mediated by a short sequence element. Genes \& Dev. 3: 803-815.

Melton, D., P.A. Krieg, M.R. Rebagliati, T. Maniatis, K. Zinn, and M.R. Green. 1984. Efficient in vitro synthesis of biolog. ically active RNA and RNA hybridization probes from plasmids containing a bacteriophage SP6 promoter. Nucleic Acids Res. 12: 7035-7056.

Mercer, J.F.B. and S.A. Wake. 1985. An analysis of the rate of metallothionein mRNA poly $(\mathrm{A})$ shortening using RNA blot hybridization. Nucleic Acids Res. 13: 7929-7943.

Mowry, K.L. and D.A. Melton. 1992. Vegetal messenger RNA localization directed by a 340-nt RNA sequence element in Xenopus oocyte. Science 255: 991-994.

Munroe, D. and A. Jacobson. 1990. mRNA poly(A) tail, a 3 enhancer of translation. Mol. Cell. Biol. 10: 3441-3455.

Murray, A.W. and M.W. Kirschner. 1989. Cyclin synthesis drives the early embryonic cell cycle. Nature 339: 275-280.

Newport, J. and M. Kirshner. 1982. A major developmental transition in early Xenopus embryos: I. Characterization and timing of cellular changes at the midblastula stage. Cell 30: 675-686.

Paris, J. and M. Philippe. 1990. Poly(A) metabolism and polysomal recruitment of maternal mRNAs during early Xenopus development. Dev. Biol. 140: 221-224.

Paris, J. and J.D. Richter. 1990. Maturation-specific polyadenylation and translational control: Diversity of cytoplasmic polyadenylation elements, influence of poly(A) tail size, and formation of stable polyadenylation complexes. Mol. Cell. Biol. 10: $5634-5645$.

Paris, J., H.B. Osborne, A. Couturier, G.R. Le, and M. Philippe. 1988. Changes in the polyadenylation of specific stable RNA during the early development of Xenopus laevis. Gene 72: 169-176.

Sagata, N, M. Oskarrson, T. Copeland. J. Brumbaugh, and G.F. Vande Woude. 1988. Function of c-mos proto-oncogene product in meiotic maturation in Xenopus oocytes. Nature 338: 519-525.
Sagata, N., I. Daar, M. Oskarsson. S.D. Showalter, and G.F. Vande Woude. 1989. The product of the c-mos proto-oncogene as a candidate initiator for oocyte maturation. Science 245: 643-645.

Sanger, F. and A. Coulsen. 1978. The use of thin polycrylamide gels for DNA sequencing. FEBS Lett. 87: 107-1 10.

Schedl, T., T.G. Burland, K. Gull, and W.F. Dove. 1984. Cell cycle regulation of tubulin RNA level, tubulin protein synthesis, and assembly of microtubules in Physarum. I. Cell Biol. 99: 155-165.

Simon, R., J.-P. Tassan, and J. Richter. 1992. Translational control by poly(A) elongation during Xenopus development: Differential repression and enhancement by a novel cytoplasmic polyadenylation element. Genes \& Dev. 6: 2580-2591.

Standart, N. 1992. Masking and unmasking of maternal mRNA. Sem. Dev. Biol. 3: 367-379.

Standart, N., M. Dale, E. Stewart, and T. Hunt. 1990. Maternal mRNA from clam oocytes can be specifically unmasked in vitro by antisense RNA complementary to the 3 '-untranslated region. Genes \& Dev. 4: 2157-2168.

Tautz, D. and C. Pfeifle. 1989. A non-radioactive in situ hybridization method for the localization of specific RNAs in Drosophila embryos reveals translational control of the segmentation gene hunchback. Chromosoma 98: 81-85.

Varnum, S.M. and W.M. Wormington. 1990. Deadenylation of maternal mRNAs during Xenopus oocyte maturation does not require specific cis-sequences: A default mechanism for translational control. Genes \& Dev. 4: 2278-2286.

Vassalli, J-D., J. Huarte. D. Belin, P. Gubler, A. Vassalli, M.L. O'Connell, L.A. Parton, R.J. Rickles, and S. Strickland. 1989. Regulated polyadenylation controls mRNA translation during meiotic maturation of mouse oocytes. Genes \& Dev. 3: 2163-2171.

Weeks, D.L., J.A. Walder, and J.M. Dagle. 1991. Cyclin B mRNA depletion only transiently inhibits the Xenopus embryonic cell cycle. Development 111: 1173-1178.

Wharton, R.P. and G. Struhl. 1991. RNA regulatory elements mediate control of Drosophila body pattern by the posterior morphogen nanos. Cell 67: 955-967.

Wickens, M. 1992. Forward, backward, how much, when: Mechanisms of poly(A) addition and removal and their role in early development. Sem. Dev. Biol. 3: 399-412.

Wickens, M.P. and P. Stephenson. 1984. Role of the conserved AAUAAA sequence: Four AAUAAA point mutations prevent $3^{\prime}$ end formation. Science 226: 1045-1051. 


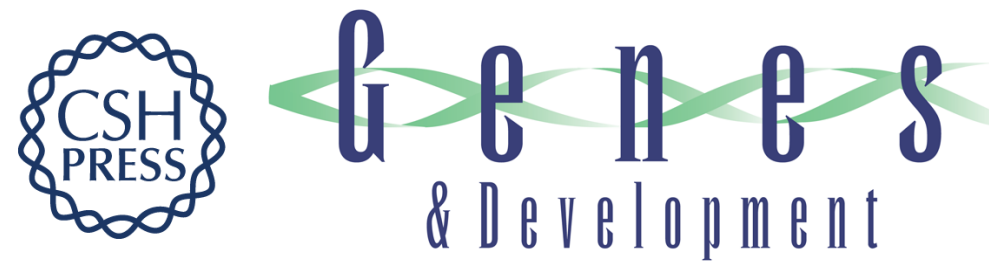

\section{The 3'-untranslated regions of c-mos and cyclin mRNAs stimulate translation by regulating cytoplasmic polyadenylation.}

M D Sheets, C A Fox, T Hunt, et al.

Genes Dev. 1994, 8:

Access the most recent version at doi:10.1101/gad.8.8.926

References This article cites 43 articles, 22 of which can be accessed free at:

http://genesdev.cshlp.org/content/8/8/926.full.html\#ref-list-1

License

Email Alerting

Service

Receive free email alerts when new articles cite this article - sign up in the box at the top right corner of the article or click here.

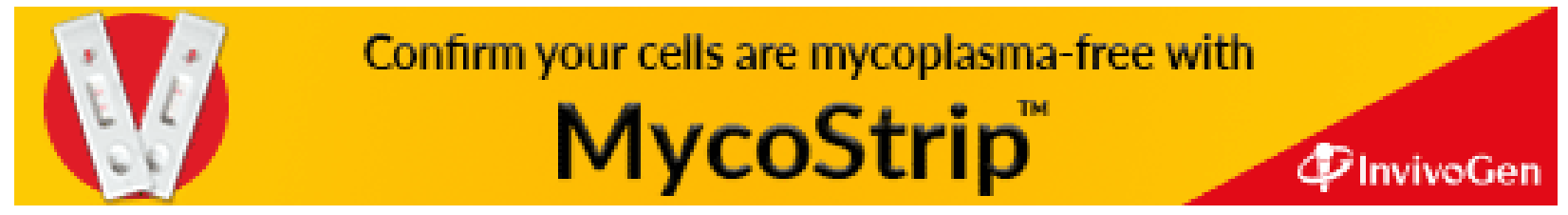

